\title{
Influence of Imperfections on Behaviour of Thin-walled Steel-concrete Composite Columns
}

\author{
Deividas MARTINAVIČIUS*, Mindaugas AUGONIS** \\ *Kaunas University of Technology, Studentu 48, 44249 Kaunas, Lithuania, E-mail: deividas.martinavicius@ktu.edu \\ **Kaunas University of Technology, Studentu 48, 44249 Kaunas, Lithuania, E-mail: mindaugas.augonis@ktu.lt \\ crossrefhttp://dx.doi.org/10.5755/j02.mech.25935
}

\section{Introduction}

Closed section steel-concrete structures are becoming increasingly popular in the construction industry as this type of structures possess various advantages compared to conventional structures. Composite structures usually have smaller cross-sections than the reinforced concrete structures and thus are more aesthetic. Smaller cross-sections also mean that additional space inside of the building is saved. Furthermore, steel-concrete structures have a higher fire resistance and stiffness than the regular steel structures. Steel profiles also serve a role of a formwork for the concrete. Thus, a relatively fast construction of the steel-concrete structures is ensured.

Thick steel profiles tend to be more expensive compared to thin profiles. However, in cases when a thin steel profile has a high width-to-thickness ratio, additional mechanical considerations are required. The regular approach to design a slender steel section is to calculate the effective cross-sectional area of the profile. The same approach is adopted by the steel structures design code Eurocode 3 [1] and composite structures design code Eurocode 4 [2]. However, it could be expected that the concrete inside of the steel profile would increase the critical buckling stress of the steel section, as the buckling is not allowed towards the inside of the cross-section. For example, the local buckling factor $k$ for the steel structures is equal to 4 [3], while significantly higher values of 9.33 [4], 10.3 [5], 10.67 [3] and 9.81 [6] were reported in cases of closed section steelconcrete columns. Subsequently, significantly higher critical buckling stresses are obtained using the latter $k$ values.

The critical buckling stress and effective area may also depend on the various factors, such as initial geometrical imperfections and residual stresses. In the literature reviewed, there was no specific information on how the effective cross-sectional area develops from the critical buckling load to the ultimate load and how exactly different types of imperfections affect the critical buckling stress and ultimate load. Thus, this research is aimed at evaluating the significance of the different types of initial imperfections.

\section{Experimental details}

\subsection{Materials and specimens}

Three composite steel-concrete columns were tested to obtain the load-displacement curves and the ultimate strengths. The columns were composed of the separate fillet-welded steel plates. Eight end stiffeners were additionally welded at both ends of the columns to avoid the "elephant foot" buckling at the significantly lower load [7]. The separate plates of the columns were initially tack welded and the internal bracing was provided. The columns were then welded with the continuous fillet welds and the internal bracing was removed. The concrete mix was poured in three pours and the concrete was consolidated using the internal electric concrete vibrator after every pour. The columns were then left for 28 days for the concrete to harden. After 28 days both ends of the columns were polished to obtain the smooth surfaces. The principal drawing and view of the column is presented in Fig. 1.
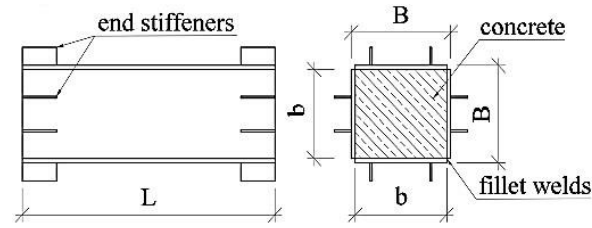

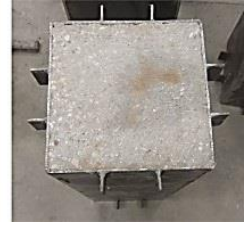

b
Fig. 1 Principal drawing (a) and view of the composite column (b)

The dimensions and material properties of the three analysed columns are presented in the Table 1 , where $B, b$, $t$ and $L$ is the outer width, inner width, thickness and length of the steel profile, respectively, $f_{y}$ and $f_{u}$ is the yield and ultimate strength of the steel, respectively, $f_{c}$ is the average compressive strength of the concrete and $E_{c}$ is the elastic modulus of the concrete.

Table 1

Dimensions and material properties of the columns

\begin{tabular}{|c|c|c|c|c|c|c|c|}
\hline $\begin{array}{c}\text { Column } \\
\text { type }\end{array}$ & $\begin{array}{c}B, \\
\mathrm{~mm}\end{array}$ & $\begin{array}{c}t, \\
\mathrm{~mm}\end{array}$ & $\begin{array}{c}L, \\
\mathrm{~mm}\end{array}$ & $\begin{array}{c}f_{y}, \\
\mathrm{MPa}\end{array}$ & $\begin{array}{c}f_{u}, \\
\mathrm{MPa}\end{array}$ & $\begin{array}{c}f_{c}, \\
\mathrm{MPa}\end{array}$ & $\begin{array}{r}E_{c}, \\
\mathrm{MPa}\end{array}$ \\
\hline 1 & 164.8 & 08 & 479 & \multirow{3}{*}{$\begin{array}{c}370.85 \\
\pm 3.82\end{array}$} & \multirow{3}{*}{$\begin{array}{c}481.58 \\
\pm 6.37\end{array}$} & $\begin{array}{l}31.66 \\
\pm 1.79\end{array}$ & 30474 \\
\hline 2 & 204.0 & 3.02 & 599.5 & & & $\begin{array}{l}32.10 \\
\pm 1.25\end{array}$ & 32204 \\
\hline 3 & 243.3 & 3.09 & 718 & & & $\begin{array}{l}26.79 \\
\pm 2.51\end{array}$ & 32176 \\
\hline
\end{tabular}

The properties of the steel was obtained by testing five "dog bone" shaped specimens according to EN ISO 6892-1 [8]. Three 100x100x100 cubic specimens for every column were tested according to EN 12390-3 [9] to obtain the compressive strength of the concrete. One 100x100x300 specimen was tested to obtain the elastic modulus of the concrete of every column according to EN 12390-13 [9].

\subsection{Test procedure}

Hydraulic press machine of the 500 tons' capacity was used to load the columns. The experimental view is presented in Fig. 2. 


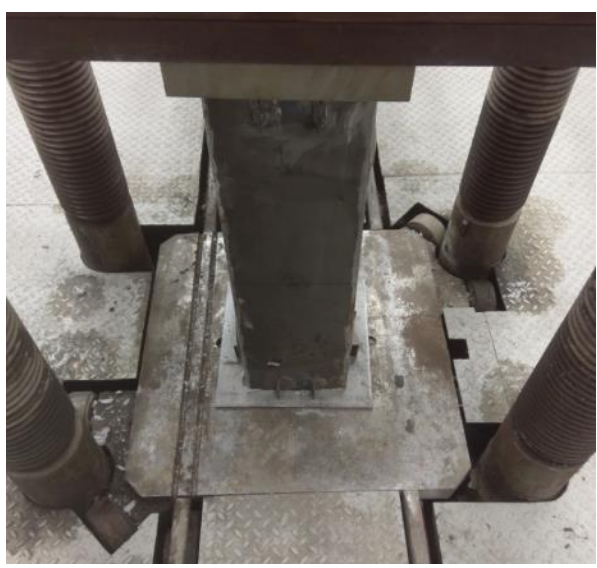

Fig. 2 Experimental view

The column was centred and two LVDT transducers were pointed to the movable base of the press. The purpose of the transducers was to measure the movement of the base, which was expected to be equal to the shortening of the column. Electronic equipment was used to write and save the results. The loading force was increased at the rate of $10 \mathrm{kN} / \mathrm{s}$. The experiment was stopped once the column lost at least $10 \%$ of the ultimate load.

\section{Finite element analysis}

In order to evaluate the influence of the imperfections and to verify the experimental results of the steel-concrete columns, finite element (FE) models were created and analysed using the finite element analysis software "ABAQUS". Two types of initial imperfections were prescribed for the FE models: residual stresses caused by the welding and initial geometrical imperfections. Geometrical imperfections may occur during the manufacturing process (cutting and welding) and transportation.

\subsection{Material models}

An idealised trilinear stress-strain curve (up to an ultimate strength) of the steel was used for the FE models. The yield stress and ultimate stress values from Table 1 were used. Young's modulus of $210 \mathrm{GPa}$ and Poisson's ratio of 0.3 [1] was assumed.

The nonlinear stress-strain curve was used for the concrete [10]. The Poisson's ratio of 0.2 [10] was assumed. Young's modulus and average concrete cubic strength values from Table 1 were used. The cubic strength value was converted to the cylinder strength using the following expression [11]:

$$
f_{c m}=\left(0.76+0.2 \log _{10} \frac{f_{c}}{19.6}\right) f_{c} .
$$

The inelastic behaviour of the concrete was modelled using the "Concrete Damaged Plasticity" (CDP) model in "ABAQUS" [12], which makes use of a non-associated plastic flow potential, based on the Drucker-Prager hyperbolic function:

$$
G=\sqrt{\left(e f_{c t m} \tan \psi\right)^{2}+q^{2}}-p \tan \psi,
$$

where: $e$ is the flow potential eccentricity of the hyperbolic function; $\psi$ is the dilation angle; $q$ is the von Mises equivalent effective stress and $p$ is the hydrostatic pressure. The dilation angle value of $20^{\circ}$ [13] and the default eccentricity value of 0.1 [12] was used.

The CDP model also considers the ratio of initial equibiaxial compressive yield stress to initial uniaxial compressive yield stress ratio $f_{b 0} / f_{c 0}$. The ratio of the second stress invariant on the tensile meridian to that on the compressive meridian $K_{c}$ is also considered by the CDP model. The default values $f_{b 0} / f_{c 0}=1.16$ and $K_{c}=2 / 3$ [12] were used.

\subsection{Imperfections}

The shape of the initial geometrical imperfections for unstiffened tubes can be assumed to have the following form [14]:

$$
\omega=\frac{\omega_{0}}{4}\left(1-\cos \frac{2 m \pi x}{B}\right)\left(1-\cos \frac{2 n \pi y}{L}\right),
$$

where: $x$ and $y$ are the lateral and longitudinal coordinates of the steel panel, respectively, assuming the bottom corner of the column as a reference point; $B$ and $L$ are the width and length of the steel panel, respectively; $m$ and $n$ are the numbers of the imperfection waves along the lateral and longitudinal directions, respectively; $\omega_{0}$ is the imperfection amplitude. The scheme of the imperfections is shown in Fig. 3.

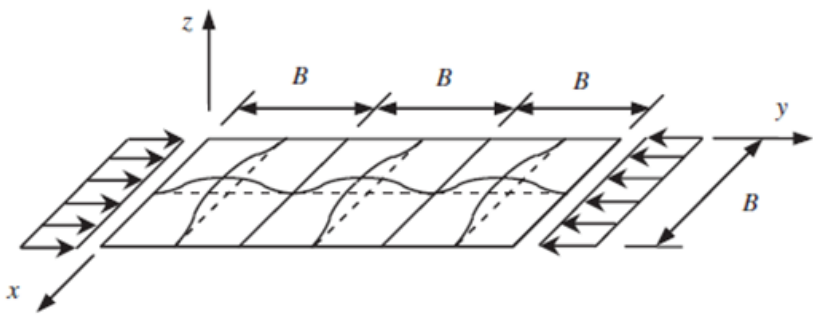

Fig. 3 Geometrical imperfections [15]

The variable $m$ is usually assumed as 1 , as one lateral half wave yields the lowest critical stress and is thus the most critical value. However, different values (1-6) of the variable $n$ are used in this research to find the most critical case. Different values of the imperfection $\omega_{0}$ are also used in this research. For example, Eurocode 3 proposes to assume this value as $B / 200$ [16]. On the other hand, some codes propose to assume the imperfection amplitude as high as $B / 100$ [17]. For the comprehensive analysis, values from $B / 100$ to $B / 500$ were used in this research.

Significant residual stresses may be caused during the process of welding. According to the model of Uy [18], tensile residual stresses equal to the yield strength of the steel are caused in the areas close to the welds. Thus, tensile stresses occur in the corners of the column. Compressive residual stresses are then caused in the middle of every steel panel of the column to balance out the equilibrium in every cross-section. The scheme is presented in Fig. 4.

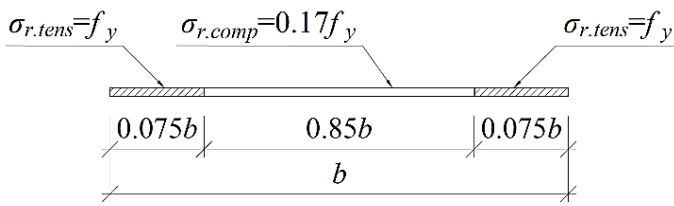

Fig. 4 Distribution of the residual stresses in the steel panel 


\subsection{FE models, mesh and boundary conditions}

Overall forty-eight FE models were created. Sixteen FE models were created for every column, assuming different types of imperfections (Fig. 5). The models were doubly symmetric, as no global buckling was expected.
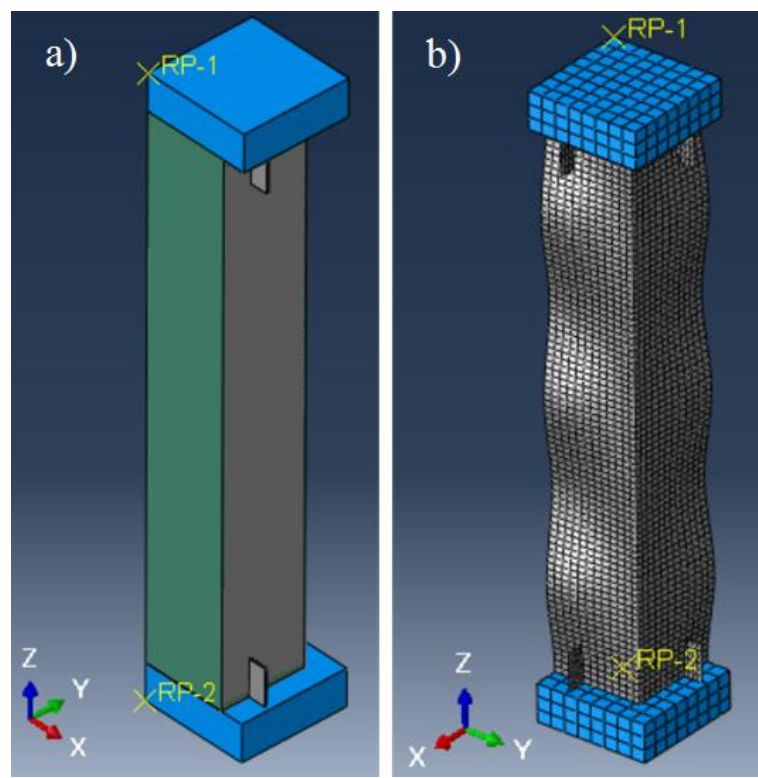

Fig. 5 Quarter FE model without the imperfections (a) and quarter FE model with scaled imperfections (b)

4 node shell elements with reduced integration were used to model the steel elements. 9 section points through the shell thickness were used. 8 node solid mesh elements with reduced integration (C3D8R) were used to model the concrete. The mesh size was selected as $\mathrm{L} / 100$ and $\mathrm{L} / 50$ for the longitudinal direction, while $\mathrm{B} / 24$ and $\mathrm{B} / 12$ were selected for the lateral directions of the steel and concrete parts, respectively [11].

Two plates were modelled in the FE models. One plate was supporting the column and the other one was used to load the specimen. Two reference points (RP-1 and RP2 ) were created in the middle axis of the column. Reference RP-1 was created at the top of the model. This reference point was tied to all the nodes at the top surface of the top plate using the kinematic coupling. Similarly, the reference point RP-2 was created at the bottom and tied to all the nodes at the bottom surface of the bottom plate. Reference point RP-2 was supported to have zero degrees of freedom and the reference point RP-1 was prescribed to have a downward displacement load.

The contact between the steel and concrete in the tangential direction was set up as a frictional behaviour with the friction coefficient of 0.57 [19]. The contact was set up as "hard" in the normal direction. Thus, the penetration of one part into another was disallowed.

\section{Results}

\subsection{Experimental results}

The experimental ultimate loads of the columns are presented in Table 2. The failure occurred at the mid-height of the columns or in the areas close to end stiffeners. The failure was ductile initially. The buckling waves started to form in the middle of the steel panels. It led to the stress distribution to the corner regions. Once the corner regions started yielding and the load started decreasing, the welds in the corners failed. Subsequently, the steel panels began separating and thus, significant decrease of the load was noticed. Once the steel panels separated, the experiment was stopped. The view of the column " 3 " after the failure is presented in Fig. 6. The load-displacement response of the columns is presented in Fig. 7.

Table 2

Ultimate strength of the columns

\begin{tabular}{|c|c|c|c|}
\hline Column type & 1 & 2 & 3 \\
\hline Ultimate strength, $\mathrm{kN}$ & 1343.4 & 1612.1 & 1930.5 \\
\hline
\end{tabular}
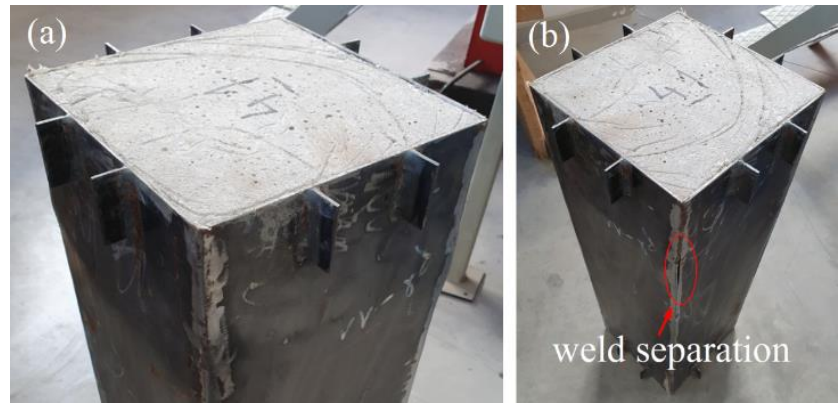

Fig. 6 Local buckling below the top stiffeners of the column (a) and corner weld separation (b)

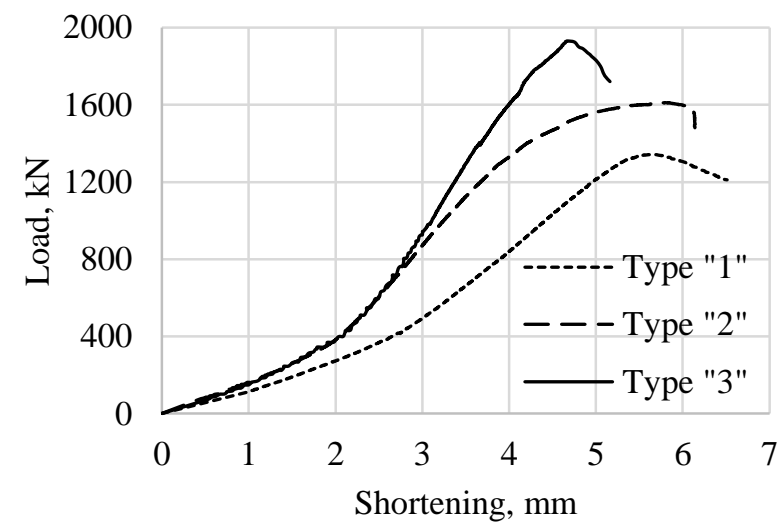

Fig. 7 Experimental load-displacement curves of the columns

\subsection{Numerical results}

The effects of the different types of imperfections on the ultimate load, critical buckling stress and development of the effective cross-sectional area of the steel profile in the composite steel-concrete columns are discussed in the following chapters.

\subsubsection{Comparison of the numerical models with the geo- metrical imperfections having a different number of imperfection waves}

Models with a different number of longitudinal imperfection waves $n$ (1-6) were created for every type of column in this section. The amplitude was selected as $B / 200$ [16]. None of the models were prescribed with the residual stresses. The results are presented in the Table 3, where $N_{\text {s.max }}$ is a maximum load resisted by the steel profile, $N_{u l t}$ is a maximum load resisted by the whole composite section, $A_{\text {eff }}$ is an effective cross sectional area of the steel profile, $A$ is an unreduced (netto) cross sectional area and $\sigma_{c r}$ is a critical buckling stress. The models with no imperfections 
$(n=0)$ were also created and assumed as reference models. The results of the latter models are written using italic font. Critical buckling stress $\sigma_{c r}$ is determined by analysing the stress development in the steel panel. Once the stress distribution becomes nonlinear, the onset of the buckling is determined. To allow some flexibility, it was decided to determine the critical buckling stress as the average stress in the steel panel at the calculation step, when at least two finite elements exceeded the deviation of $10 \%$ from the average stress in the steel panel. The stress development in the steel panel of the column $240 \times 240 \times 3$ with four $(n=4)$ imperfection waves is presented in Fig. 8. This shape was found to yield the lowest resistance for this column. The stress distributions at the different loads are shown. The effective areas of the steel profiles $A_{\text {eff }}$ are calculated using Eq. 4.

$$
A_{e f f}=4 \cdot \frac{\sum_{i=1}^{24} A_{i} \sigma_{N, i}}{f_{y}} \text {, }
$$

where: $A_{i}$ is the cross-sectional area and $\sigma_{N, i}$ is the normal stress of the separate finite elements. The multiplier of four is selected, because the quarter models were analysed.

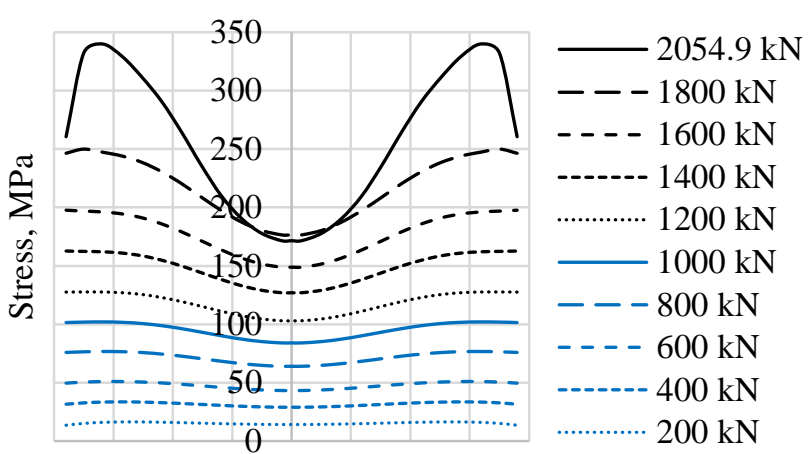

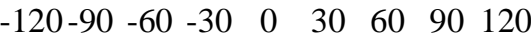

Steel panel coordinates, $\mathrm{mm}$

Fig. 8 Development of the stresses in the steel panel of the column Type "3" $(n=4)$

Varying the number of geometrical imperfection waves $n$ of the columns, it was noticed that the most unfavourable cases were obtained when four or five waves were modelled. Geometrical imperfections decreased the ultimate resistance of the wide and slender steel profiles by up to $16 \%$ and up to $10 \%$ for more compact profiles. The decrease of the critical buckling stress was even more critical - up to $51 \%$, compared to the reference models.

Table 3

Comparison of the numerical models with the different number of geometrical imperfection waves

\begin{tabular}{|c|c|c|c|c|c|c|c|}
\hline Imp. wave number & 0 (ref. model) & 1 & 2 & 3 & 4 & 5 & 6 \\
\hline \multicolumn{8}{|c|}{ Type "1". $B=164.8 \mathrm{~mm}$} \\
\hline$N_{\text {s.max }}, \mathrm{kN}$ & 657.2 & 653.9 & 638.1 & 613.1 & 597.3 & 592.7 & 594.2 \\
\hline$N_{\text {s.max }} / N_{\text {s.max.ref }}$ & $100.0 \%$ & $99.5 \%$ & $97.1 \%$ & $93.3 \%$ & $90.9 \%$ & $90.2 \%$ & $90.4 \%$ \\
\hline$N_{u l t}, \mathrm{kN}$ & 1354.3 & 1363.4 & 1360.0 & 1319.5 & 1305.4 & 1300.1 & 1303.2 \\
\hline $\operatorname{Max} A_{\text {eff }} / A$ & 0.929 & 0.924 & 0.902 & 0.866 & 0.844 & 0.838 & 0.840 \\
\hline$\sigma_{c r}, \mathrm{MPa}$ & 344.4 & 342.7 & 334.4 & 290.5 & 259.5 & 253.5 & 258.1 \\
\hline$\sigma_{c r} / \sigma_{c r . r e f}$ & $100.0 \%$ & $99.5 \%$ & $97.1 \%$ & $84.3 \%$ & $75.3 \%$ & $73.6 \%$ & $74.9 \%$ \\
\hline \multicolumn{8}{|c|}{ Type "2". $B=204.0 \mathrm{~mm}$} \\
\hline$N_{\text {s.max }}, \mathrm{kN}$ & 782.2 & 791.7 & 742.5 & 699.4 & 678.9 & 677.9 & 685.5 \\
\hline$N_{\text {s.max }} / N_{\text {s.max.ref }}$ & $100.0 \%$ & $101.2 \%$ & $94.9 \%$ & $89.4 \%$ & $86.8 \%$ & $86.7 \%$ & $87.6 \%$ \\
\hline$N_{u l t}, \mathrm{kN}$ & 1862.7 & 1885.3 & 1866.8 & 1797.7 & 1784.7 & 1782.7 & 1788.9 \\
\hline $\operatorname{Max} A_{\text {eff }} / A$ & 0.888 & 0.898 & 0.843 & 0.794 & 0.771 & 0.769 & 0.778 \\
\hline$\sigma_{c r}, \mathrm{MPa}$ & 329.2 & 333.2 & 312.5 & 272.7 & 258.6 & 257.9 & 264.4 \\
\hline$\sigma_{c r} / \sigma_{c r . r e f}$ & $100.0 \%$ & $101.2 \%$ & $94.9 \%$ & $82.8 \%$ & $78.6 \%$ & $78.3 \%$ & $80.3 \%$ \\
\hline \multicolumn{8}{|c|}{ Type "3". $B=243.3 \mathrm{~mm}$} \\
\hline$N_{\text {s.max }}, \mathrm{kN}$ & 882.9 & 913.8 & 816.5 & 763.1 & 740.0 & 747.7 & 756.6 \\
\hline$N_{\text {s.max }} / N_{\text {s.max.ref }}$ & $100.0 \%$ & $103.5 \%$ & $92.5 \%$ & $86.4 \%$ & $83.8 \%$ & $84.7 \%$ & $85.7 \%$ \\
\hline$N_{u l t}, \mathrm{kN}$ & 2151.3 & 2188.1 & 2141.2 & 2068.1 & 2054.9 & 2054.6 & 2059.3 \\
\hline $\operatorname{Max} A_{\text {eff }} / A$ & 0.837 & 0.866 & 0.774 & 0.724 & 0.702 & 0.709 & 0.717 \\
\hline$\sigma_{c r}, \mathrm{MPa}$ & 304.8 & 299.7 & 280.4 & 159.8 & 148.2 & 162.0 & 193.0 \\
\hline$\sigma_{c r} / \sigma_{c r . r e f}$ & $100.0 \%$ & $98.3 \%$ & $92.0 \%$ & $52.4 \%$ & $48.6 \%$ & $53.1 \%$ & $63.3 \%$ \\
\hline
\end{tabular}

\subsubsection{Comparison of the numerical models with the geo-} metrical imperfections having a different amplitude

Finite element models with the different amplitudes of the geometrical imperfection waves were analysed in this section. The amplitudes were varied for the models with the most unfavourable number of imperfection waves. Thus, five $(n=5)$ waves were modelled for the column type "1" and " 2 ". Four $(n=4)$ waves were used for the column type " 3 ". Imperfection values from $B / 100$ to $B / 500$ were used. None of the latter models were prescribed with the residual stresses. The results are presented in the Table 4.

The imperfection amplitude $B / 100$ may be consid- ered to be excessive, as the stresses in the separate finite elements show considerable deviations from the average stress in the web from the very first step of the FE analysis. Thus, the critical buckling stress was not determined in this case. Imperfections with the amplitude $B / 100$ have also reduced the ultimate strength of the steel profile by up to $23 \%$, compared to the reference models. Models with the imperfection amplitude $B / 200$ have shown more reasonable results, which were described in the previous chapter. The difference between the effective cross-sectional areas of the models with the imperfection amplitudes $B / 300$ and $B / 500$ was less significant - only up to $4 \%$. Similarly, the difference of the critical stresses was up to $10 \%$. 
Table 4

Comparison of the numerical models having different imperfection amplitudes

\begin{tabular}{|c|c|c|c|c|c|c|}
\hline Imp. amplitude & 0 (ref. model) & $\mathrm{B} / 100$ & $\mathrm{~B} / 200$ & $\mathrm{~B} / 300$ & $\mathrm{~B} / 400$ & $\mathrm{~B} / 500$ \\
\hline \multicolumn{7}{|c|}{ Type "1". $B=164.8 \mathrm{~mm}$} \\
\hline$N_{\text {s.max }}, \mathrm{kN}$ & 657.2 & 535.8 & 592.7 & 616.4 & 628.9 & 636.0 \\
\hline$N_{\text {s.max }} / N_{\text {s.max.ref }}$ & $100.0 \%$ & $81.5 \%$ & $90.2 \%$ & $93.8 \%$ & $95.7 \%$ & $96.8 \%$ \\
\hline$N_{u l t}, \mathrm{kN}$ & 1354.3 & 1263.8 & 1300.1 & 1317.2 & 1328.3 & 1334.9 \\
\hline $\operatorname{Max} A_{\text {eff }} / A$ & 0.929 & 0.757 & 0.838 & 0.871 & 0.889 & 0.899 \\
\hline$\sigma_{c r}, \mathrm{MPa}$ & 344.4 & - & 253.5 & 308.5 & 325.2 & 333.4 \\
\hline$\sigma_{c r} / \sigma_{c r . r e f}$ & $100.0 \%$ & - & $73.6 \%$ & $89.6 \%$ & $94.4 \%$ & $96.8 \%$ \\
\hline \multicolumn{7}{|c|}{ Type "2". $B=204.0 \mathrm{~mm}$} \\
\hline$N_{\text {s.max }}, \mathrm{kN}$ & 782.2 & 607.2 & 677.9 & 710.1 & 729.6 & 742.7 \\
\hline$N_{\text {s.max }} / N_{\text {s.max.ref }}$ & $100.0 \%$ & $77.6 \%$ & $86.7 \%$ & $90.8 \%$ & $93.3 \%$ & $94.9 \%$ \\
\hline$N_{u l t}, \mathrm{kN}$ & 1862.7 & 1747.7 & 1782.7 & 1802.2 & 1814.1 & 1822.8 \\
\hline $\operatorname{Max} A_{\text {eff }} / A$ & 0.888 & 0.689 & 0.769 & 0.806 & 0.828 & 0.843 \\
\hline$\sigma_{c r}, \mathrm{MPa}$ & 329.2 & - & 257.9 & 292.4 & 307.0 & 312.6 \\
\hline$\sigma_{c r} / \sigma_{c r . r e f}$ & $100.0 \%$ & - & $74.9 \%$ & $84.9 \%$ & $89.1 \%$ & $90.8 \%$ \\
\hline \multicolumn{7}{|c|}{ Type " 3 ". $B=243.3 \mathrm{~mm}$} \\
\hline$N_{\text {s.max }}, \mathrm{kN}$ & 882.9 & 677.7 & 740.0 & 766.3 & 782.7 & 793.9 \\
\hline$N_{\text {s.max }} / N_{\text {s.max.ref }}$ & $100.0 \%$ & $76.8 \%$ & $83.8 \%$ & $86.8 \%$ & $88.6 \%$ & $89.9 \%$ \\
\hline$N_{u l t}, \mathrm{kN}$ & 2151.3 & 2026.8 & 2054.9 & 2066.5 & 2074.2 & 2080.0 \\
\hline $\operatorname{Max} A_{\text {eff }} / A$ & 0.837 & 0.643 & 0.702 & 0.727 & 0.742 & 0.753 \\
\hline$\sigma_{c r}, \mathrm{MPa}$ & 304.8 & - & 148.2 & 241.1 & 260.5 & 272.1 \\
\hline$\sigma_{c r} / \sigma_{c r . r e f}$ & $100.0 \%$ & - & $48.6 \%$ & $79.1 \%$ & $85.5 \%$ & $89.3 \%$ \\
\hline
\end{tabular}

4.2.3. Comparison of the numerical models with the different types of imperfections

Additional models with residual stresses were created and analysed in this section. One model was prescribed residual stresses only. Five more models had residual stresses combined with the geometrical imperfections to evaluate the least favourable cases. The results are presented in Table 5.

Models with residual stress only had an up to $13 \%$ lower effective cross-sectional area combined to the reference models. A similar decrease of the critical buckling stress was also observed.

Table 5

Comparison of the numerical models with the combined imperfections

\begin{tabular}{|c|c|c|c|c|c|c|c|}
\hline Imp. amplitude & 0 (ref. model) & 0 & $\mathrm{~B} / 100$ & $\mathrm{~B} / 200$ & $\mathrm{~B} / 300$ & $\mathrm{~B} / 400$ & $\mathrm{~B} / 500$ \\
\hline Residual stresses & No & Yes & Yes & Yes & Yes & Yes & Yes \\
\hline \multicolumn{8}{|c|}{ Type "1". $B=164.8 \mathrm{~mm}$} \\
\hline$N_{\text {s.max }}, \mathrm{kN}$ & 657.2 & 642.2 & 517.9 & 549.5 & 562.8 & 571.2 & 577.2 \\
\hline$N_{\text {s.max }} / N_{\text {s.max.ref }}$ & $100.0 \%$ & $97.7 \%$ & $78.8 \%$ & $83.6 \%$ & $85.6 \%$ & $86.9 \%$ & $87.8 \%$ \\
\hline$N_{\text {ult }}, \mathrm{kN}$ & 1354.3 & 1265.7 & 1228.2 & 1243.3 & 1249.1 & 1252.8 & 1255.3 \\
\hline $\operatorname{Max} A_{\text {eff }} / A$ & 0.929 & 0.908 & 0.732 & 0.777 & 0.795 & 0.807 & 0.899 \\
\hline$\sigma_{c r}, \mathrm{MPa}$ & 344.4 & 336.6 & - & 244.5 & 274.6 & 287.8 & 291.0 \\
\hline$\sigma_{c r} / \sigma_{c r . r e f}$ & $100.0 \%$ & $97.7 \%$ & - & $71.0 \%$ & $79.7 \%$ & $83.6 \%$ & $84.5 \%$ \\
\hline \multicolumn{8}{|c|}{ Type "2". $B=204.0 \mathrm{~mm}$} \\
\hline$N_{\text {s.max }}, \mathrm{kN}$ & 782.2 & 694.3 & 579.8 & 617.4 & 632.4 & 641.9 & 649.0 \\
\hline$N_{\text {s.max }} / N_{\text {s.max.ref }}$ & $100.0 \%$ & $88.8 \%$ & $74.1 \%$ & $78.9 \%$ & $80.9 \%$ & $82.1 \%$ & $83.0 \%$ \\
\hline$N_{u l t}, \mathrm{kN}$ & 1862.7 & 1757.1 & 1712.4 & 1726.9 & 1733.4 & 1737.7 & 1742.1 \\
\hline $\operatorname{Max} A_{e f f} / A$ & 0.888 & 0.788 & 0.658 & 0.701 & 0.718 & 0.729 & 0.737 \\
\hline$\sigma_{c r}, \mathrm{MPa}$ & 329.2 & 289.8 & - & 196.4 & 243.0 & 259.1 & 266.4 \\
\hline$\sigma_{c r} / \sigma_{c r . r e f}$ & $100.0 \%$ & $88.0 \%$ & - & $59.7 \%$ & $73.8 \%$ & $78.7 \%$ & $80.9 \%$ \\
\hline \multicolumn{8}{|c|}{ Type “3”. $B=243.3 \mathrm{~mm}$} \\
\hline$N_{\text {s.max }}, \mathrm{kN}$ & 882.9 & 771.5 & 648.4 & 677.5 & 689.7 & 697.0 & 702.1 \\
\hline$N_{\text {s.max }} / N_{\text {s.max.ref }}$ & $100.0 \%$ & $87.4 \%$ & $73.4 \%$ & $76.7 \%$ & $78.1 \%$ & $78.9 \%$ & $79.5 \%$ \\
\hline$N_{\text {ult }}, \mathrm{kN}$ & 2151.3 & 2023.7 & 1993.6 & 2004.6 & 2008.8 & 2010.6 & 2011.1 \\
\hline $\operatorname{Max} A_{\text {eff }} / A$ & 0.837 & 0.731 & 0.615 & 0.642 & 0.654 & 0.661 & 0.666 \\
\hline$\sigma_{c r}, \mathrm{MPa}$ & 304.8 & 262.3 & - & 71.9 & 203.2 & 224.1 & 235.5 \\
\hline$\sigma_{c r} / \sigma_{c r . r e f}$ & $100.0 \%$ & $86.1 \%$ & - & $23.6 \%$ & $66.7 \%$ & $73.5 \%$ & $77.3 \%$ \\
\hline
\end{tabular}

It was observed that the residual stresses combined with the $B / 100$ amplitude geometrical imperfections reduced the effective cross-sectional area by up to $27 \%$ in case of the most slender column. However, this kind of amplitude may be considered excessive. Thus, assuming a maximum amplitude of $B / 200$, the reduction of the effective cross-sectional area was up to $23 \%$. In this case, the reduction of the critical buckling stress was up to $74 \%$. Considering the overall composite behaviour, the ultimate resistance of the columns was reduced by up to $10 \%$, compared to the columns with no imperfections. 


\section{Discussion}

The initial imperfections are often omitted when creating and analysing the FE models. However, it is found in this research that the residual stresses and geometrical imperfections have a considerable impact on the performance of the composite thin-walled steel-concrete columns. Initial imperfections reduce the critical buckling stress significantly, which leads to the early stress redistribution and loss of the stiffness of the steel profile. A significant decrease of the effective cross-sectional area is also observed, which leads to the reduced ultimate strength. The comparison of the numerical and experimental ultimate strengths is presented in the Table 5, where $N_{\text {ult.exp }}$ is the experimental ultimate strength, $N_{\text {ult.num.min }}$ and $N_{\text {ult.num.max }}$ are the minimum and maximum numerical ultimate strengths, respectively.

Table 6

Comparison of the ultimate strengths

\begin{tabular}{|c|c|c|c|}
\hline Column type & 1 & 2 & 3 \\
\hline$N_{\text {ult.exp }}, \mathrm{kN}$ & 1343.4 & 1612.1 & 1930.5 \\
\hline$N_{\text {ult.num.min }}, \mathrm{kN}$ & 1228.2 & 1712.4 & 1993.6 \\
\hline$N_{\text {ult.num.max }}, \mathrm{kN}$ & 1354.3 & 1862.7 & 2151.3 \\
\hline$N_{\text {ult.num.min }} / N_{\text {ult.exp }}, \%$ & 91.4 & 106.2 & 103.3 \\
\hline$N_{\text {ult.num.max }} / N_{\text {ult.exp }}, \%$ & 100.8 & 115.5 & 111.4 \\
\hline
\end{tabular}

It was noticed that the geometrical imperfections allowed to modify the ultimate strength of the composite columns by approximately $10 \%$. Considering only the behaviour of the steel profile in the composite column, the imperfections had an even more significant impact, which was discussed in the previous chapter.

The experimental ultimate strength of the column " 1 " was only $0.8 \%$ lower compared to the numerical model with no imperfections. The experimental resistance of the column " 2 " and column " 3 " was $3.3 \%$ and $6.2 \%$ lower, respectively, compared to the least favourable numerical cases. The slightly lower experimental resistance could be explained by the possible uncertainty of the concrete strength.

Using the obtained numerical results and limiting the imperfection amplitude to $B / 200$, the expressions for the calculation of the critical stress $\sigma_{c r}$ and effective area ratio $A_{\text {eff }} / A$ can be proposed. The numerical results and the curves of the proposed expressions are presented in Figs. 9 and 10. The expressions are valid for the $b / t$ ratios in the range of 50-77. The thickness of the steel profile is limited to $3 \mathrm{~mm}$. The width is limited to $160-245 \mathrm{~mm}$. Additional experimental tests and numerical models are necessary to expand the aforementioned thickness and width ranges and to evaluate the adaptability of the expressions for other steel and concrete classes.

Proposed critical stress calculation formula:

$$
\sigma_{\text {cr.prop }}=-0.308 \cdot\left(\frac{b}{t}\right)^{2}+32.7 \cdot\left(\frac{b}{t}\right)-623 \text {, }
$$

where: $b$ is the inner width of the steel profile and $t$ is the thickness of the steel profile.

Proposed effective area to unreduced (netto) area ratio calculation formula:

$$
\frac{A_{\text {eff }}}{A}=-0.0054 \cdot\left(\frac{b}{t}\right)+1.054,
$$

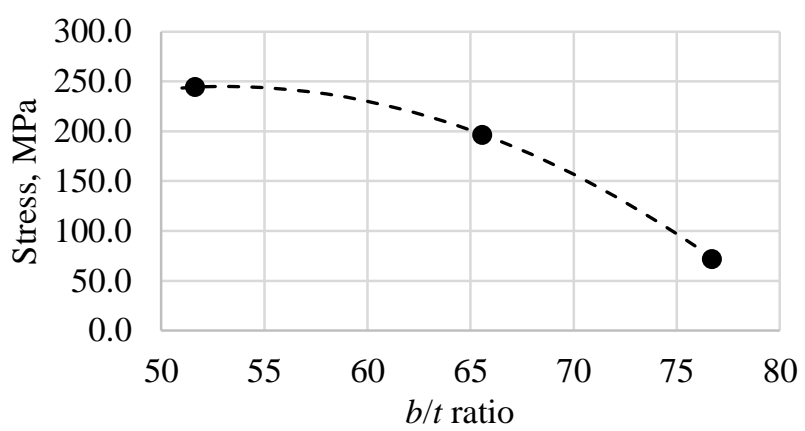

- Critical stress of the FE model

- - - - Proposed approximation curve

Fig. 9 Critical stress $-b / t$ ratio dependency

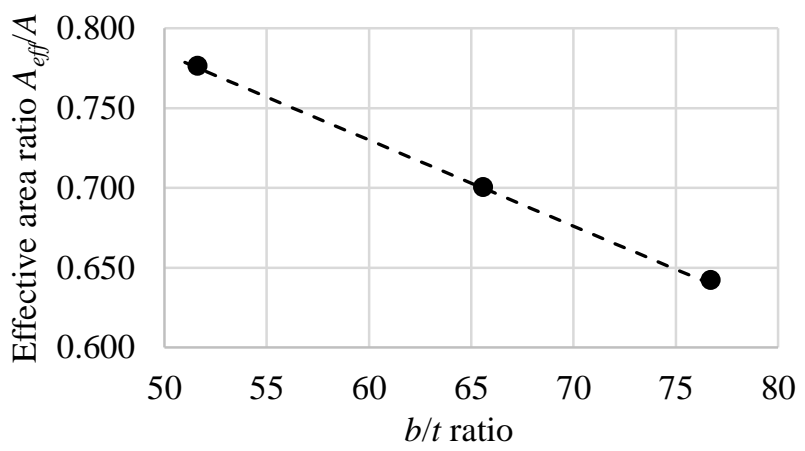

- Effective area ratio of the FE model

- - - Proposed approximation curve

Fig. 10 Effective area ratio- $b / t$ ratio dependency

\section{Conclusions}

Experimental and numerical investigation was carried out. The main conclusions can be drawn:

1. Inclusion of the initial geometrical imperfections with the $B / 200$ amplitude in the FE models reduced the resistance of the steel section in the composite column by up to $16 \%$. The critical buckling stress reduction was up to $51 \%$.

2. Inclusion of the residual stresses in the FE models reduced the resistance of the steel section in the composite column by up to $13 \%$. The critical buckling stress reduction was up to $14 \%$.

3 . Inclusion of the geometrical imperfections (amplitude $B / 200$ ) combined with the residual stresses in the FE models reduced the resistance of the steel section in the composite column by up to $23 \%$. The critical buckling stress reduction was up to $74 \%$. The expressions for the calculation of the critical buckling stress and effective area ratio were proposed.

4. The ultimate resistance of the composite steelconcrete columns was reduced by up to $10 \%$ by including the imperfections.

\section{References}

1. EN 1993-1-1:2005. Eurocode 3: Design of steel structures - Part 1-1: General rules and rules for buildings. CEN, Brussels, May 2005.

2. EN 1994-1-1:2004. Eurocode 4: Design of composite steel and concrete structures - Part 1-1: General rules and rules for buildings. CEN, Brussels, Dec. 2004. 
3. Timoshenko, S.; Gere, J.M. 2009. Theory of Elastic Stability.-Dover: Dover Publications Inc. 560 p.

4. Faxén, O. H. 1935. Die knickfestigkeit rechteckiger platten, Zeitschrift für Angewandte Mathematik und Mechanik 15(5): 268-277 (in German). https://doi.org/10.1002/zamm.19350150505.

5. Uy, B.; Bradford, M. A. 1996. Elastic local buckling of steel plates in composite steel-concrete members, Engineering Structures 18(3): 193-200. https://doi.org/10.1016/0141-0296(95)00143-3.

6. Liang, Q. Q.; Uy, B. 2000. Theoretical study on the post-local buckling of steel plates in concrete-filled box columns, Computers and Structures 75: 479-490. https://doi.org/10.1016/S0045-7949(99)00104-2.

7. Uy, B. 2001. Local and postlocal buckling of fabricated steel and composite cross sections, Journal of Structural Engineering 127(6): 666-677. https://doi.org/10.1061/(ASCE)07339445(2001)127:6(666).

8. EN ISO 6892-1. Metallic materials. Part 1: Method of test at room temperature. CEN, Brussels, Nov. 2019.

9. EN 12390-13. Testing hardened concrete. Part 13: Determination of secant modulus of elasticity in compression. CEN, Brussels, Oct. 2013.

10. EN 1992-1-1:2004. Eurocode 2: Design of concrete structures - Part 1-1: General rules and rules for buildings. CEN, Brussels, Oct. 2004

11. Duarte, A. P. C.; Silva, B. A.; Silvestre, N.; Brito, J.; Júlio, E.; Castro, J. M. 2016. Finite element modelling of short steel tubes filled with rubberized concrete, Composite Structures 150: 28-40. https://doi.org/10.1016/j.compstruct.2016.04.048.

12. ABAQUS/CAE User's Manual, Version 6.14. 2013. Rhode Island, USA.

13. Ellobody, E.; Young, B.; Lam, D. 2006. Behaviour of normal and high strength concrete-filled compact steel tube circular stub columns, Journal of Constructional Steel Research 62(7): 706-715. https://doi.org/10.1016/j.jcsr.2005.11.002.

14. Wright, H. D. 1995. Local Stability of Filled and Encased Steel Sections, Journal of Structural Engineering 121(10): 1382-1388. https://doi.org/10.1061/(ASCE)07339445(1995)121:10(1382).

15. Tao, Z.; Uy, B.; Han, L. H.; Wang, Z. B. 2009. Analysis and design of concrete-filled stiffened thin-walled steel tubular columns under axial compression, ThinWalled Structures 47(12): 1544-1556. https://doi.org/10.1016/j.tws.2009.05.006.

16. EN 1993-1-5:2006. Eurocode 3: Design of steel structures - Part 1-5: Plated structural elements. CEN, Brussels, Oct. 2006.

17. GB 50018-2002. Technical code of cold-formed thinwall steel structures. Ministry of Construction of the People's Republic of China, Beijing, Sep. 2002.

18. Uy, B. 2000. Strength of Concrete Filled Steel Box Columns Incorporating Local Buckling, Journal of Structural Engineering 126(3): 341-352. https://doi.org/10.1061/(ASCE)07339445(2000)126:3(341).

19. Rabbat, B. G.; Russell, H. G. 1985. Friction Coefficient of Steel on Concrete or Grout, Journal of Structural Engineering 111(3): 505-515. https://doi.org/10.1061/(ASCE)07339445(1985)111:3(505).

\section{Martinavičius, M. Augonis}

\section{INFLUENCE OF IMPERFECTIONS ON BEHAVIOUR OF THIN-WALLED STEEL-CONCRETE COMPOSITE COLUMNS}

S u m m a r y

This paper presents experimental and numerical analysis of the composite steel-concrete columns. Three columns are tested experimentally. Overall forty-eight FE models are created. Sixteen different models for every experimental column are analysed to evaluate the influence of the different types of imperfections. It was found that the imperfections reduced the resistance of the composite columns by up to $10 \%$. Limiting the geometrical imperfection amplitudes to $B / 200$, the steel profile effective cross-sectional area reduction by up to $23 \%$ was observed, while the critical buckling stress was reduced by up to $74 \%$. Expressions for the calculation of the effective cross-sectional area ratio and critical buckling stress are proposed.

Keywords: thin-walled steel section, steel-concrete composite column, geometrical imperfections, residual stresses.

Received April 27, 2020 Accepted February 17, 2021

This article is an Open Access article distributed under the terms and conditions of the Creative Commons Attribution 4.0 (CC BY 4.0) License (http://creativecommons.org/licenses/by/4.0/). 